\title{
Achieving Vision 20: 2020: The Role of the Nigerian Capital Market
}

\author{
Oke, Margaret Adebimpe \\ Department Of Economics Ajayi Crowther University, Oyo. Oyo State Nigeria.
}

\begin{abstract}
This study examined the role of the Nigerian Capital Market in achieving the vision 20: 2020 in Nigeria. However, the main aim of vision 20:2020 is to improve the standard of living of the average Nigerian. Applying co-integration and error correction modeling to stock market performance and per capital income time series data, this study has helped in highlighting the specific roles of major indicators of the capital market, which are relevant in testing the stock market-economic growth nexus. The findings indicate the separate roles played by the primary capital market and the secondary capital market in the growth of the Nigerian economy are capable of achieving vision 20:2020. By and large, the evidence from this study revealed that while activities in the secondary capital market tend to grow the Nigerian economy through its wealth effect that of the primary market ironically did not.
\end{abstract}

Keywords: Achieving Vision 20:2020, Nigerian capital market, Standard of living, Economic growth, Economic development and Stock prices.

\section{Introduction}

In an extensive work done by Goldman Sachs in 2001, he projected that he economies of Brazil, Russia, India and China (BRIC) would surpass that of the G6 based on extrapolation of growth rate, demographic changes, capital accumulation, diminishing return with development and exchange rates management. He identified Nigeria as one of the economies in Africa that has the potential of becoming one of the20 largest economies by 2020 and that Nigeria poised to emerge as part of the next eleven "N11" economies after the BRIC. To achieve the vision 2020 Nigeria must maintain an annual average growth rate of $12.4 \%$ over the next 15 years and translate the growth into meaningful development. Moreover, Nigeria must focus on more economic reform, structural reforms; and political and governance reforms. Nigeria must also take steps towards greater integration into world trade and finance, create more industrial economy and eliminate over dependence on primary commodities. The Nigeria business environment must be improved and increase commitment to education, improve power supply, transportation and telecommunication infrastructure.

The financial sector of the economy is to serve as the driver and catalyst to achieving the vision and to help attain full diversification of the economy. The idea is to strengthen the domestic financial market by developing competence and skills for financial services industry, improve access to finance and build an integrated infrastructure for the financial industry. Create a vibrant capital market and help more Nigerian make more money through the market. The financial market is the medium through which funds are mobilized and channeled efficiently from savers to users of funds. It function through the interplay of individuals, institutions and instrument. It performs the important function of providing the needed finance for the provision of essential goods and services to bring about economic growth and development. It consists of two major segments-the money market and the capital market. The money market provides finance on short-term basis to individuals, businesses, enterprises, government and their agencies, while the capital market, on the other hand, provides finance to corporate bodies, governments and their agencies on medium to long-term basis.

The capital market is a network of specialized financial institutions, series of mechanisms, processes and infrastructure that, in various ways, facilitate the bringing together of suppliers and users of medium to long-term capital for investment in socio-economic developmental projects. It embraces all the arrangements that facilitate the buying and selling of securities. The capital market has two segments, the Primary Market provides the avenue through which governments and corporate bodies raise fresh funds through the issuance of securities. It is otherwise known as the new issues market. Fresh funds can be raised through a combination of ways. These include public offers, rights issues and private placements. The secondary market provides investors the opportunity to buy or sell securities that were earlier issued in the primary market. The secondary market can be organized or unorganized. An organized market is a stock market with physical location, trading in designated (quoted) securities. Example of this is The Nigerian Stock Exchange. An unorganized market has no physical trading location but transactions are conducted mainly through telephone calls and the computer. It is called an Over-the-Counter-Market (OTC). The OTC trades mainly in unquoted securities. The distinguishing factor between the two segments is that in the primary markets, the funds raised from investors go to the issuing entity, while in the secondary market; the proceeds from the transaction to investors. 
There are a lot of investment opportunities available in the Nigerian Capital Market. The ultimate aim is to create wealth and improve the welfare of the average Nigerian, which automatically translates in the nation's per capita income. We use econometric techniques to ascertain the relationship between stock market earnings and per capita income. We poised to establish the role of Nigeria capital market in achieving vision 20:2020. The rest of the paper is divided into four sections. In section II, relevant theoretical and empirical studies rare reviewed while the methodology of the study is explained in section III. The findings of this study are presented section IV while section $\mathrm{V}$ contains the concluding remarks.

\subsection{Literature Review and Theoretical Framework}

The stock market has been identified as an institution that contributes to the economic growth of emerging economies, they are also considered as a variable in explaining the economic growth in the mostdeveloped ones. The study of Goldsmith (1969) is an essential reference, although since the nineties the direction of causality between economic growth and financial development has always been argued. Stock Exchanges play an increasingly important role, not only for channeling resources, but also for promoting reforms to modernize the financial sector legislation as is experienced in Nigeria and other emerging economies. In a study published at the beginning of the nineties, Levien (1991) points out two key arguments on how stock exchanges speed up the economic growth. The first is by making property changes possible in the companies, whilst not affecting their productive process; the second is by offering higher possibilities of portfolio diversification to the agents.

Atje and Jovanovic (1993) present a cross country study of stock market and economic growth over the period 1980-1988. They found a significant correlation between average economic growth and stock market capitalization for 40 countries. In a similar study by Levine and Zervos (1998), they employed data on 47 countries from 1976 through 1993 and found that measures of stock market liquidity are strongly related to growth, capital accumulation and productivity while stock market size does not seem to be robustly correlated to economic growth. Conversely, bank lending to the foreign direct investment has a strong effect on economic growth. Harris (1997) re-examined the empirical relationship between stock market and economic growth using appropriate instruments for investment. In contrast to Atje and Jovanovic (1993), he found no hard evidence that the level of stock market activity helps to explain growth in per capita output. Slitting the sample leads to the similar results for the sub-samples of less developed countries.

On this subject, the study of Levine and Zervos (1996) suggests that he level of stock exchange development is positively associated to economic development. In later research, the same authors (1998a) property in advanced economies eases the efficient allocation of resources, the capital formation and the economic growth. Also Demirguc-Kunt and Maksimovic (1998) cited in Henry (2000), found a relationship between economic growth and the stock market activity in the field of transmission of securities (secondary market) more than in funds channeling (new issue so primary market). Demirguc-Kunt and Maksimovic (1996), with a sample of 30 countries for the 1980-1991 period, drew the following conclusions: stock market advances in emerging countries do not imply a decrease of banking systems. Banks and stock markets do not appear, as alternative or rival institutions, but are complementary to each other, reinforcing the whole activity of the financial system.

This idea of complementary is reinforced in the research carried out by Demirguc-Kunt and Levine (1996) using data from 44 countries, either emerging or industrial, for the years 1986-1993. The different measures of stock exchange size are strongly correlated to other indicators of activity levels of financial, banking non-banking institutions, as well as to insurance companies and pension funds: they concluded that "countries with well-developed stock markets tend to also have well-developed financial intermediaries". Bartov (1992) highlighted the relationship that exists between stock prices and expected earnings using the earnings expectation models to predict expected earnings. Oludoyi (2001) also demonstrated that he current price of a stock equals expected value of the sum of next periods price and dividend discounted to the present at the rate ' $r$ ' with an expected value of random variable in his model given as: $\mathrm{Pt}=(1+\mathrm{r})-\mathrm{nEt}\left(\mathrm{P}_{\mathrm{t}+1}+\mathrm{d}_{t+1}+\mathrm{W}_{\mathrm{t}+1}\right)$. This he further explained has significant effect on the wealth of the Nation.

Barlett (2000), states that rising stock prices have two main effects on the economy; first, it raises wealth in the economy. This increase in wealth raises the amount of consumer spending and thereby increases the wealth of the nation. Secondly, rising stock prices can increase investment spending. We see that one way a firm can finance investment spending is to issue stock. If stock prices rise, it can raise more money per share of the stock issued. He further added that he main mechanism through which the stock market affects the economy is the so-called wealth effect. A standard 'rule of thumb' is that every $\$ 1$ increase in stock market wealth boosts consumer spending by 3 to 7 cents per year, with a common point estimate being 4 cents. According to him, this happens because a rise in stock market wealth encourages consumers to cut back on savings or increase their debt, and increase their spending on consumption goods. Conversely, a fall in the market causes them to cut back on consumption by a similar magnitude". 
Irving (2004) considered the links between stock exchanges and overall socio-economic development to be tenuous, nonexistent or even harmful. He advised African countries not to devote further scarce resources and efforts to promoting stock exchange, since there are many weightier problems to address in Africa: high poverty levels, inadequate social services and undeveloped infrastructure. Even if the resources were available, stock markets could expose already fragile developing economies to the stabilizing effects of short-term, speculative capital inflows. Demirguc-Kunt and Asli (1996), examined the relationship between stock market earning and economic growth, they found out that there is a positive relationship but not a very strong one.

\subsection{Sources, Data Description and Method of Analysis}

\section{Methodology}

The study employed secondary data obtained from the Security and Exchange Commission database and the IMF/World Bank database. The time series data cover the period 1980-2007. In an attempt to investigate the role of the Nigerian Stock Market in achieving vision 2020, which has the ultimate aim of increasing the standard of living of the average Nigerian by improving their income, we apply co-integration and error correction modeling to the data obtained. We indeed ascertain the link between stock market earnings and income of the average Nigerian. Thus, we use the per capita income (PCI) as the proxy for income of the average Nigerian which is our dependent variable and stock market capitalization (MC), price earnings ratio (PER), Dividend Yield (DY) and number of listed securities (NLS) as stock market performance variables, as our explanatory variables. Since most of the time series data are non-stationary, we decided to carry out the unit root tests for stationarity. According to Granger and Newbold (1974), and Engle and Granger (1987), the application of OLS to non-stationary data would result in spurious regression. To determine if the time series data is stationary linear combination is called the cointegrating equation and may be interpreted as a stable longrun (equilibrium) relationship among the nonstationary time series variable. It also ignores the short run dynamics that might cause the relationship not to hold in the short run.

Cointegration test can be conducted through Engle and Granger (1987) two-step test or the maximum likelihood method developed by Johansen (1995). In this study, we employ the Johansen technique because it performs better when we are dealing with multiple regressions. Finally, we use the error correction model to correct for disequilibrium and show the adjustment from short run to long rune equilibrium

\subsection{The Model}

The model is based on Demirguc-Kunt, Asli and Levine (1996) theory on the relationship between stock market earnings and economic growth, it is modify to measure the impact the stock market on the income of the average Nigerian. We specify as follows:

$\mathrm{PCI}=\beta_{0}+\beta_{1} \mathrm{MC}+\beta_{2} \mathrm{PER}+\beta_{3} \mathrm{NLS}+\mathrm{Ui}$

Where: PCI - Per Capital Income, MC - Market Capitalization, PER- Price earning Ratio, DY- Dividend Yield, NSL -Number of Listed Securities.

Per Capital Income (PCI) is measured by dividing the real GDP of a particular year by the population of the country. This is our dependent variable; MC represents market capitalization, which signifies the size of the market. It should have a positive co-efficient. Per Earning Ratio (PER) measures the appropriateness of the pricing of securities listed on the exchange and Dividend Yield measures the Yield on investment is such securities. Number of listed Securities measures number of security available for transaction in the market.

$\beta_{0}, \beta_{1}, \beta_{3}$ and $\beta_{4}$ are unknown parameters and $\mathrm{Ui}$ is the disturbance term. On apriori, we expect b1 $>0, \beta_{2}>0, \beta_{3}$ $>0, \beta_{4}>0$.

\subsection{The Estimated Results and Discussion}

As already stated, the estimated regression results are based on the Johansen cointegration technique and the Vector Error Correction Mechanism (VECM). These results are presented and discussed in this section. The procedure involves the investigation and determination of the time series properties of all variables included in the regression model. The appropriate test here is the unit root test which in this case is based on the Augmented Dickey-Fuller (ADF) test which provides the framework for the determination of the order of integration of each time series and consequently the (Non) Stationarity of same. We estimate relation (1) using the econometric software E Views 5.1 provided by Quantitative Micro Software. The results of the unit root test for Stationarity is presented in table 1.0 below: 
Table 1: Results of Unit Root Test for Stationarity

\begin{tabular}{|c|c|c|c|c|c|c|c|}
\hline \multirow[t]{2}{*}{ Variable } & \multirow[t]{2}{*}{ Lag } & \multicolumn{2}{|c|}{ Coefficient } & \multicolumn{2}{|c|}{ ADF critical value } & \multirow{2}{*}{$\begin{array}{l}\text { Order of } \\
\text { integration }\end{array}$} & \multirow[t]{2}{*}{ Remarks } \\
\hline & & Level & $1^{\text {st }}$ Difference & 1 percent & 5 percent & & \\
\hline PCI & 0 & -2.4980 & $-4.0794 *$ & -3.6998 & -2.9763 & $/(1)$ & Stationary \\
\hline PER & 5 & -0.6094 & $-5.1113 *$ & -3.7880 & -3.0124 & $/(1)$ & Stationary \\
\hline NLS & 0 & -2.1270 & $-6.0654^{*}$ & -3.6998 & -29763 & $/(1)$ & Stationary \\
\hline $\mathrm{MC}$ & 2 & -2.1690 & $4.9069 *$ & -3.7880 & -3.0123 & $/(1)$ & Stationary \\
\hline DY & 0 & -1.3867 & $-3.6382 * *$ & -3.6998 & -2.9763 & $/(1)$ & Stationary \\
\hline
\end{tabular}

The results of the unit root test for Stationarity are presented in table 1 above. As shown in the table, it can be seen that all the time series are integrated of order one meaning that they are first differenced stationary. The optimum lag length, which is a guide for model selection, are reported in column two of the table and were selected on the basis of the Schwarz criterion (SC). This provides a basis for the test for cointegrating relationships among the stationary series of the same order. We next proceed to conduct the test for cointegration as follows:

\subsection{Testing for Cointegration}

We apply the Johansen cointegration framework by beginning with a simple autoregressive process of order $\mathrm{p}, \mathrm{AR}(\mathrm{p})$ model which is generated from a stochastic process, $\mathrm{y}_{\mathrm{t}}$, as follows:

$$
\mathrm{Y}_{\mathrm{t}}=\phi_{\mathrm{t}} \mathrm{y}_{\mathrm{t}-1}+\ldots \phi_{\mathrm{p}} \mathrm{Y}_{\mathrm{t}-\mathrm{p}}+\mu+\mathrm{C}_{\mathrm{t}}
$$

It is convenient to rewrite relation (2) in error correction format such that both the non-contemporaneous relationship between the variables and the lagged difference are combined to obtain:

$$
\begin{aligned}
& \Delta \mathrm{y}_{\mathrm{t}}=\prod \mathrm{y}_{\mathrm{t}-1}+\quad \Gamma_{\mathrm{t}} \Delta \mathrm{y}_{\mathrm{t}-1}+\mu+\epsilon_{\mathrm{t}}, \\
& \text { Where: } \\
& \Gamma_{\mathrm{t}}=\left(\phi_{1}+\phi_{2}+\ldots+\phi_{\mathrm{t}}\right)^{-1}-1_{\mathrm{n}} \text { for } \mathrm{i}=1,2 \ldots \mathrm{p}-1 \\
& \prod=\phi_{1}+\phi_{2}+\ldots+\phi_{\mathrm{p}}-1_{\mathrm{n}} \\
& \mathrm{t}=1
\end{aligned}
$$

All the terms coequation (2) are assumed to be generated by a random walk process and hence, are 1(1), therefore, equation (3) includes only $1(0)$ variables and a white nose error term. $\prod$ is the coefficient matrix and contains information on the possible cointegrating relations between the $n$ elements of the stochastic process, $y_{t}$. Now, if the $\phi_{\mathrm{t}}$ has eigen-values close to unity, then $\prod$ has eigen values close to zero implying that $\prod$ is close to rank deficiency, meaning that there may be cointegration. This of course provides a compelling need for an appropriate statistical method to investigate whether the rank of $\prod$ differs significantly from zero or from $\mathrm{n}$.

A convenient way to model several time series simultaneously is to use a Vector Auto Regression, or VAR model (Davidson and MacKinnon, 1999). One such appropriate methodology developed by Johansen (1998, 1991, 1995) is based on the unrestricted VAR model and is employed in this study. This method essentially amounts to a multivariate extension of the univariate Augmented Dickey-Fuller (ADF) method.

$$
\sum_{t=1}^{p-1}
$$

Three very interesting cases expectedly should arise from the VAR model in relation (3) as follows:

(i) The matrix $\prod$ can be the zero matrix meaning that there is no cointegration. Any linear combination of $\mathrm{y}_{\mathrm{t}}$ will be stationary.

(ii) The matrix $\prod$ can have full rank, $\mathrm{n}(\mathrm{r}=\mathrm{n})$. Any linear combination of $\mathrm{y}_{\mathrm{t}}$ will be stationary.

(iii) The matrix $\prod$ can have rank deficiency or reduced rank, i.e. $0<\mathrm{r}<\mathrm{n}$. here, the rank of $\mathrm{r}$ becomes the number of linearly independent cointegrating relations among the variables in $\mathrm{y}_{\mathrm{t}}$.

The third case may be decomposed as: $\Pi=\mathrm{a} \beta$. In this case, a and $\beta$ are defined as ( $\mathrm{x}$ r) parameter matrices. The matrix $\beta$ contains the $r$ cointegrating relations while the matrix contains the adjustment parametser. The Johansen maximum likelihood cointegration testing method aims to test the rank of the matrix $\prod$ using the reduced rank regression technique based on canonical correlations (Franses, 1998). The two basic test statistics used in this procedure for the detection of the number of cointegrating vectors are the trace statistic and the maximum eigen-value statistic. We however employ the trace test (which is based on the likelihood ratio test) in this study. 
We now present the results of the cointegration test using the Johansen methodology, which in this case is based on the likelihood ratio test, in table 2 below:

Table 2: Result of the cointegration test using the Johansen methodology

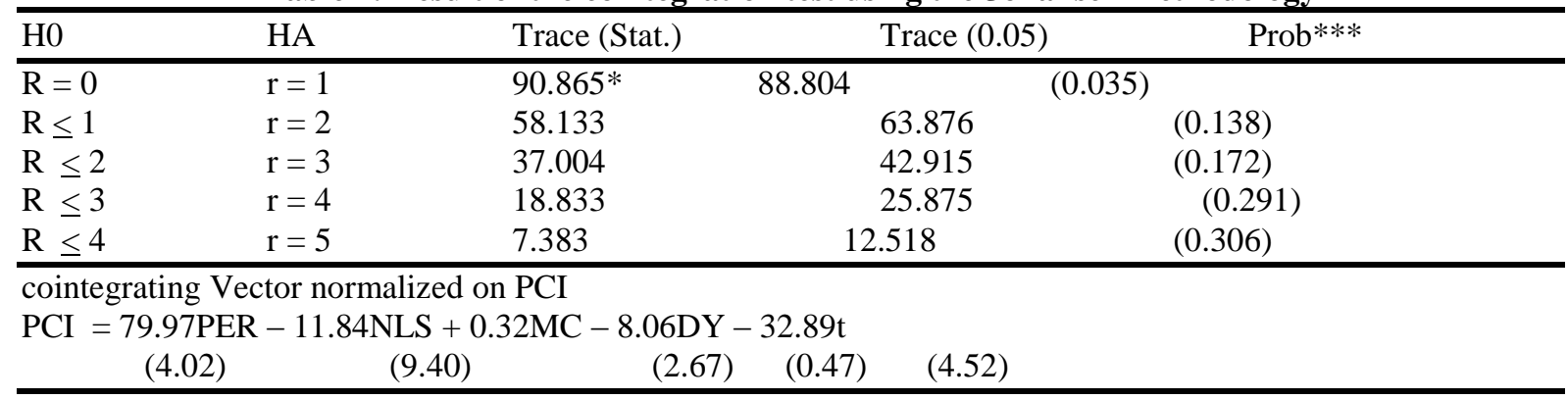

Notes:

- Trace test indicate 1 conitegrating equation at the 0.05 level

- $\quad * * *$ McKinnon-Haug-Michelis (1999) p-values

- * Indicates statistical significance at the $5 \%$ level

- The critical values for trace are taken from Osternward -Lenum (1992).

The summary of the conitegration results based on the Johansen methodology is presented in table 2 above. Relying on the trace test statistic, an examination of the results shows that the model failed to reject the null of zero cointegrating equation $(\mathrm{r}=0)$. However, there is sufficient empirical evidence to accept the null at most one $\left(\mathrm{r}^{-} \leq 1\right)$ cointegrating equation. Interestingly, this is suggest of the presence of unique cointegrating vector between PCI, PCR, NLS, MC, DY, as well as the trend variable t.

The estimates of the normalized cointegrating vector are reported at the botton of table 2 . The related $t-$ statistics are reported is curly brackets below each coefficient. The existence of a unique cointegrating vector here implies that equilibrium relationship exists among the co integrating variables and that no matter the fluctuation in the short -run; these variables have a tendency to return to this equilibrium path in the long run. In other words, given an initial disequilibrium, the cointegrating variables will not wander away from one another endlessly but will eventually return to its established equilibrium path.

The variables are all individually significant at the percent level judging from the t-statistic. The however, is with the exception of the dividend yield (DY) variable which failed the significance test even at the 10 percent level, what this means is that price earning ration and market capitalization significantly impacts positively on per capita income while number of securities listed and time trend significantly impacts negatively on per capita income over the long-run horizon. This finding early agrees with Demirgue-knut and Maksimovic (1998) where a relationship between economic growth and the stock market activity in the field of transmission of securities (secondary market). Was found to be more than that which exists for funds channeling (new issues or primary market). The implication of this result for policy is that growth in the secondary market helped to move the Nigerian economy in a positive direction more than growth in primary market during period under view. The growth transmission process occurred primary through the wealth effect. The negative impact result for number of shares listed over time is interestingly not very surprising considering the fact that most investment in stocks in the primary market do not often translates into investment in the real sector and hence have little or no welfare implication for the people. In other words, what actually constitute welfare for the people lies in the activities of the secondary capital market, which has the capacity to boost aggregate demand and consequently enhance the well-being of the people. Another line of argument here may be that the growth of the primary capital market may be mean the withdrawal of funds from more efficient sees into less efficient sectors and this definitely will lead to loss of welfare for people. The existence of a cointegratin relationship and the fact of periodic fluctuations from the equilibrium path require that we employ an error correction mechanism in order to determine how much of the errors generated in each period is corrected in subsequent periods within the framework of this model.

\subsection{VECTOR ERROR CORRECTION MODEL}

Error correction mechanism (ECM) was first used by Sargan (1962) and later popularized by Engle and Granger (1987) to correct for diseqiulibrium in a cointegrating relationship. May exist among two or more cointegrated series, in the short run, there may still be disequilibrium. The error correction mechanism serves as a means of reconciling such short-run behaviour of an economic variable with its long-run behaviour. Relation 
(3) is expanded to constitute the basic model, which we employed to develop a vector error correction model. The result of the vector error correction model is presented in table three below

Table 3: Vector Correction Estimates

\begin{tabular}{|c|c|c|c|c|c|c|}
\hline \multirow[t]{2}{*}{ Dependent Variable } & \multirow[t]{2}{*}{$\mathrm{ECT}_{\mathrm{t}-1}$} & \multicolumn{3}{|c|}{$\stackrel{\mathrm{m}}{\sum} \varphi_{\mathrm{m}} \Delta \mathrm{DPCI} \sum^{\mathrm{m}} \psi_{\mathrm{m}} \Delta \mathrm{PER} \sum_{\mathrm{m}}^{\mathrm{m}} \eta \mathrm{m} \Delta \mathrm{NLS}$} & \multicolumn{2}{|c|}{ 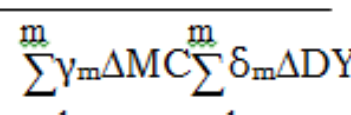 } \\
\hline & & $\frac{n=1}{0.614}$ & $n=1$ & $\begin{array}{l}n=1 \\
-10641\end{array}$ & $\frac{n=1}{2.284}$ & $\frac{n=1}{-20.071}$ \\
\hline$\triangle \mathrm{PCI}$ & {$[-1.83]^{* *}$} & (2) & (2) & (2) & (2) & (2) \\
\hline \multirow[t]{2}{*}{$\triangle \mathrm{PER}$} & -0.01 & 0.007 & -998 & 0.133 & 0.03 & 0.549 \\
\hline & {$[-2 \cdot 39]^{*}$} & (2) & (2) & (2) & (2) & (2) \\
\hline \multirow[t]{2}{*}{$\Delta \mathrm{NLS}$} & -0.07 & 0.038 & -11.84 & 0.32 & 0.23 & -2.59 \\
\hline & {$[-1.85]^{* *}$} & (2) & (2) & (2) & (2) & (2) \\
\hline \multirow[t]{2}{*}{$\Delta \mathrm{MC}$} & $2.848^{*}$ & -2.89 & 406.17 & -43.46 & -6.92 & -11.84 \\
\hline & [4.82] & (2) & (2) & (2) & (2) & (2) \\
\hline \multirow[t]{2}{*}{$\Delta \mathrm{DY}$} & 0.003 & 0.003 & 0.6141 & -0.015 & -0.017 & -0.30 \\
\hline & {$[0.81]$} & (2) & (2) & (2) & (2) & (2) \\
\hline
\end{tabular}

- $\mathrm{ECT}_{\mathrm{t}-1}$ Represents the one period lagged error correction term from the cointegrating equation.

- Figures is square bracket below each error correction coefficient are the asyotituc-t ratio and those in curly bracket below the coefficients of the differenced no-cibtenoarabeiys elements are the standard errors.

- * And** indicate significant at 5 percent and 10 percent levels respectively.

The error correction estimates presented in table three above reveal that of the five equations, three are correctly signed with the expected negative sign meaning that, there is convergence towards the equilibrium path following disequilibrium in each period. The equations representing PCI, PER, and NLS are in this category. The error correction term (ECT) or speed of adjustment coefficient for these equations is also significant. This means that a meaningful error correction is taking place in these equations with significant results. The ECT for the other two equations (MC and DY) are wrongly signed with positive ECT. In this case any error generated in each period has every tendency to explode or wander further away from the equilibrium path over time. Interestingly, about sixty six percent of the errors generated in the previous period is corrected in the current period in the PCI equation. However, only about one percent and seven percent of such error is corrected in the PER and NLS equations respectively. This is despite the fact that the error term has a significant coefficient.

\subsection{Concluding Remarks}

A number of studies on the role of the stock market in the economic growth process exist in the literature. Mixed evidence regarding the link between economic growth and stock market growth abound. While some are in support of a positive link, others do not find any empirical evidence in support of such conclusion. Specifically, some of the studies are in support of a negative link between economic growth and stock market growth. In line with the above controversy, we employ Nigerian data to provide further empirical evidence on the role of the capital market in the realization of economy and development in Nigeria. The recent consolidation exercises of major financial institutions and privatization exercises of most publicly owned enterprises are key indicators of government's faith in the capital market to drive the growth of the economy.

Using the Johansen cointegration framework and the vector error correction mechanism, this study has helped in highlighting the specific roles of major indicators of the capital market, which are relevant in testing the capital market-economic growth nexus. The major indicators of the capital market employed in this study includes: market capitalization, per-capita earning ratio, dividends yield, and number of listed securities. These served as explanatory variables while per capita income was used as a proxy for economic growth. Our findings corroborate existing literature. Market capitalization and per capita earning ratio have positive association with economic growth in the long-run and were found to be statistically significant dividend yield was not statistically significant even at the ten percent level. However, number of listed shares and time trend (an additional regressor introduced in the model) were negatively signed and also found to be statistically significant. These results place emphasis on the separate roles played by the primary capital market and the 
secondary capital market in the growth of the Nigerian economy. In other words, activities in the secondary capital market tend to grow the Nigerian economy while that of the primary market ironically do not. This result of the performance of the primary market calls for further studies.

\section{References}

[1]. Atje, R. and Jovanovic, B. (1993): "Stock Markets and Development", European Economic Review, Vol. 37, Pp. 632-640.

[2]. Barlett, B. (2000): "Opinion Editorial on the Effect of Stock Market on the Economy, National Centre for Policy Analysis, February 2000 .

[3]. Bartov, E. (1992): Pattern in Unexpected Earnings as an Explanation for Post Announcement Drift. Accounting Review 67 (3), Pg,. $610-211$.

[4]. Demirgue-Kunt, Asli and Levine, R. (1996): Stock Market Development and Financial Intermediaries: Stylized Facts. World Bank Economic Review 19(2), Pg. 281-322, May.

[5]. Engle, R. F. and C.W.J. Granger (1987): Spurious Regressions in Econometrics”, Journal of Econometrics, Vol. 2, Pp. 111-120.

[6]. Harris, R.D.F. (1997): "Stock Markets and Development: A Re-Assessment”, European Economic Review, 1. Pp. 139-136.

[7]. Henry, P.B. (2000): Do Stock Market Liberalization Cause Investment Booms "Journal of Financial Economics, 58 , Pp. 301 -334.

[8]. Irving, J. (2001) Africa's Struggling Exchanges-Boost to Economic Development of Costly Irrelevance?" Africa Recovery, Abidjan.

[9]. Johansen, Soren (1995): Likelihood-based Inference in Co-integrated Vector Autoregressive Models, Oxford University.

[10]. Levine, R. and Zervos, s. (1996) Stock Market Development and Long-run Growth. Policy Research Working Paper, World Bank, March.

[11]. Levine, R. and Zervos, S. (1998): “Stock, Markets, Banks and Economic Growth", American Economic Review, 88(3), Pp. 537-58.

[12]. Oludoyi, B. (2001) The Existence of post-earnings Announcement Drift on Returns in Nigeria Stock Exchange: Fact or Fiction? Nigeiran Journal of Economic and Social Studies, Vol. 43, No. 1, March 2001. 